\title{
PORTAS FECHADAS NO MEIO ABERTO: EDUCAÇÃO DE JOVENS COM RESTRIÇÃO DE LIBERDADE
}

\author{
DOORS CLOSED IN THE OPEN ENVIRONMENT: EDUCATION OF YOUNG PEOPLE WITH RESTRICTIONS ON \\ FREEDOM
}

PUERTAS CERRADAS EN EL MEDIO ABIERTO: EDUCACIÓN DE JÓVENES CON RESTRICCIÓN DE LIBERTAD

\author{
KOERICH, Bruna Rossi ${ }^{1}$ \\ VIDAL, Alex da Silva ${ }^{2}$
}

\section{RESUMO}

Este artigo busca investigar de que forma se apresentam os desafios para a continuidade da trajetória escolar de jovens em cumprimento de medida socioeducativa no meio aberto, entendida como um fator de restrição de liberdade. Utiliza-se, como fonte de dados, relatos de acompanhamento realizados com jovens em duas unidades de execução de medidas de prestação de serviços à comunidade. Os relatos foram analisados à luz das discussões sobre estigma social, especialmente nos referenciais de Goffman, Elias, Scotson e Foucault. A análise dos relatos sugere que as portas da educação escolar fecham para aqueles jovens que carregam consigo a marca da infração juvenil, mesmo no meio aberto.

Palavras-chave: Medidas Socioeducativas. Estigma. Juventude. Educação.

\section{ABSTRACT}

This article seeks to investigate the way in which challenges are presented for the continuity of the school trajectory of young people in compliance with socio-educational measures in the open environment, understood as a restriction of freedom. We used follow-up reports from young people in two units to implement measures to provide services to the community as data source.

The reports were analyzed in light of the discussions on social stigma, especially in the referents of Goffman, Elias, Scotson and Foucault. The analysis of the reports suggests that the doors of school education close for those young people who carry the mark of juvenile offenses even in the open environment.

Key words: Socio-educational Measures. Stigma. Youth. Education.

\section{RESUMEN}

Este artículo busca investigar de qué forma se presentan los desafíos para la continuidad de la trayectoria escolar de jóvenes en cumplimiento de medida socioeducativa en el medio abierto, entendida como un factor de restricción de libertad. Se utiliza como fuente de datos relatos de seguimiento realizados con jóvenes en dos unidades de ejecución de medidas de prestación de servicios a la comunidad.Los relatos fueron analizados a la luz de las discusiones sobre estigma social, especialmente en los referentes de Goffman, Elias, Scotson y Foucault. El análisis de los relatos sugiere que las puertas de la educación escolar cierran para aquellos jóvenes que llevan consigo la marca de la infracción juvenil, incluso en el medio abierto.

Palabras clave: Medidas Socioeducativas. Estigma. Juventud. Educación.

\footnotetext{
${ }^{1}$ Centro de Promoção da Criança e do Adolescente - CPCA - Porto Alegre - Rio Grande do Sul - Brasil

${ }^{2}$ Centro Interdisciplinar de Educação Social e Socioeducação - CIESS - Porto Alegre - Rio Grande do Sul - Brasil
} 


\section{INTRODUÇÃO}

Este artigo insere-se nos debates acerca da garantia do direito à educação para adolescentes e jovens em conflito com a lei, tendo em vista que a sua inserção ou passagem pelas medidas socioeducativas, seja de internação ou de meio aberto, torna-se, muitas vezes, uma barreira para a efetivação desse direito. Essa constatação é importante na medida que um dos principais objetivos destas medidas é exatamente a inclusão destes jovens em um sistema de garantia de direitos.

O Estatuto da Criança e do Adolescente, promulgado em 1991, considerado o principal marco jurídico contemporâneo voltado para essa população, considera o ato infracional uma conduta descrita como crime ou contravenção penal e dispõe sobre os direitos, as garantias e as possibilidades de intervenção sobre os adolescentes que o cometeram. Para esses jovens de até 18 anos (considerados penalmente inimputáveis) são previstas as medidas socioeducativas.

De acordo com o ECA, verificada a prática de ato-infracional, a autoridade competente poderá aplicar seis modalidades diferentes de medidas socioeducativas: Advertência; Obrigação de reparar o dano; Prestação de serviços à comunidade; Liberdade assistida; Inserção em regime de semiliberdade; Internação em estabelecimento educacional. (1991, p. 54) Essas modalidades são divididas em dois grandes grupos: as medidas que envolvem privação de liberdade (inserção em regime de semiliberdade e internação em estabelecimento educacional) e as demais que são chamadas de medidas de meio aberto.

O quadro a seguir demonstra a descrição geral de cada uma das modalidades de medida socioeducativa, presente no ECA:

Quadro 1 - Modalidades de Medida Socioeducativa previstas no ECA

\begin{tabular}{|c|c|l|}
\hline Caráter & Modalidade & \multicolumn{1}{c|}{ Descrição } \\
\hline \multirow{2}{*}{\begin{tabular}{c} 
Meio \\
\cline { 2 - 3 }
\end{tabular}} & Advertência & Admoestação verbal, que será reduzida a termo e assinada. \\
\cline { 2 - 4 } & $\begin{array}{c}\text { Obrigação de } \\
\text { reparar os danos }\end{array}$ & $\begin{array}{l}\text { Restituição da coisa, ressarcimento do dano, compensação do } \\
\text { prejuízo da vítima. }\end{array}$ \\
\cline { 2 - 3 } & $\begin{array}{c}\text { Prestação de } \\
\text { Serviços à } \\
\text { Comunidade }\end{array}$ & $\begin{array}{l}\text { Realização de tarefas gratuitas de interesse geral, por período } \\
\text { não excedente a seis meses, junto a entidades assistenciais, } \\
\text { hospitais, escolas e outros estabelecimentos congêneres, bem } \\
\text { como em programas comunitários ou governamentais. }\end{array}$ \\
\hline
\end{tabular}

Reflexão e Ação [ISSN 1982-9949]. Santa Cruz do Sul, v. 27, n. 2, p. 77-94, mai./ago. 2019. https://online.unisc.br/seer/index.php/reflex/index 


\begin{tabular}{|c|c|l|}
\hline & $\begin{array}{c}\text { Liberdade } \\
\text { Assistida }\end{array}$ & $\begin{array}{l}\text { Acompanhamento, auxílio e orientação do adolescente por } \\
\text { parte do orientador, visando a sua promoção social, o } \\
\text { monitoramento de sua frequência e desempenho escolar e a } \\
\text { inserção no mercado de trabalho. }\end{array}$ \\
\hline $\begin{array}{c}\text { Meio } \\
\text { Fechado }\end{array}$ & Semiliberdade & $\begin{array}{l}\text { Regime de restrição da liberdade, que envolve a realização de } \\
\text { atividades externas, independente de autorização judicial. }\end{array}$ \\
\cline { 2 - 4 } & Internação & $\begin{array}{l}\text { Medida privativa da liberdade, sujeita aos princípios de } \\
\text { brevidade, excepcionalidade e respeito à condição peculiar de } \\
\text { pessoa em desenvolvimento. }\end{array}$ \\
\hline
\end{tabular}

Fonte: Elaboração própria.

Segundo dados do Levantamento do Sistema Nacional de Atendimento Socioeducativo, o Brasil contava em 2014 com 65.649 adolescentes e jovens em cumprimento de medidas de meio aberto e 24.628 em regimes de privação ou de semi-liberdade. (BRASIL, 2017, p.15). Apesar de abarcar um significativo número de jovens, a execução de medidas socioeducativas de meio aberto ainda é um campo acadêmico pouco explorado, sendo necessárias reflexões acerca do seu funcionamento.

Mesmo que muitas vezes o conceito de restrição de liberdade se refira apenas às medidas de semiliberdade, acreditamos que o conceito abarque a execução de todas as medidas em que a liberdade do jovem é de alguma forma cerceada ou controlada, a partir da imposição de obrigações a serem executadas. Dessa forma, as medidas de liberdade assistida e de prestação de serviços à comunidade são também aqui consideradas como de restrição de liberdade.

Este artigo busca refletir acerca da garantia do direito à educação na execução das medidas socioeducativas de meio aberto a partir da experiência de duas unidades de execução de prestação de serviços à comunidade.

Grande parte dos jovens acompanhados estava infrequente no sistema formal de ensino, e possuía uma alta distorção idade/ano escolar. No entanto, quando eram questionados sobre a importância da escola, afirmavam a sua necessidade da escolarização para "se tornar alguém na vida", "para aprender e conseguir um bom emprego". Ou seja, víamos ali, se não o desejo, a percepção da importância da escola para um projeto de futuro.

Pesquisas apontam que a escolarização de jovens em conflito com a lei é bastante complexa. Numa pesquisa realizada em 2014 com adolescentes privados de liberdade (NARDI et tal, 2014), se constatou que a maioria estava entre a $5^{\mathrm{a}}$ e $7^{\mathrm{a}}$ séries, o que demonstra uma defasagem escolar quando 
observada a média de idade dos participantes. Essa defasagem pode ser explicada pelo percentual de expulsão da escola $(31,5 \%)$ e, mais ainda, pela reprovação escolar $(91,6 \%)$. Se olharmos os dados atuais da $\operatorname{FASE}^{3}$ (2017), percebemos que a grande maioria dos jovens $(86,2 \%)$ não havia completado o ensino fundamental e que a maioria dos jovens estava entre o quinto e oitavo ano, mesmo que $97,3 \%$ deles tenham mais de 15 anos $^{4}$

Outro aspecto importante a considerar é que vivemos um avanço lento, mas significativo nas últimas décadas quanto à universalização do ensino para todas as crianças e adolescentes. Dados da Pesquisa Nacional de Amostra por Domicílios (IBGE, 2013) mostram que 98,2\% da população de 06 a 14 anos estão matriculadas nas escolas. No entanto, na faixa etária de 15 a 17 anos, a taxa de matriculados na escola cai para $84,2 \%$, sendo que somente $40 \%$ estão no nível correspondente a sua faixa etária. Os números de matriculados caem ainda mais, para 51,4\%, quando a faixa etária é de 18 a 19 anos.

Todos os dados apresentados acima demonstram que a permanência do jovens no sistema formal de ensino apresenta-se como um "nó" na educação contemporânea. E que algumas parcelas dessa juventude são particularmente mais afetadas pela exclusão do sistema escolar. Apesar do avanço na escolarização nas últimas décadas, muitos jovens seguem tendo seu direito à educação negligenciada.

Em pesquisa anterior (VIDAL, 2014) constatou-se que os jovens em conflito com a lei eram estigmatizados a partir da figura do "menor infrator", construída durante o século XX, o que dificultava a sua circulação na cidade e o acesso às políticas públicas, incluindo a escola. Ao serem vistos como perigosos, incapazes, descartáveis e indesejáveis, estes jovens têm muitas vezes seus direitos negados, sendo identificados pela sociedade como sujeitos a se combater, isolar, transformar e eliminar.

A figura do "menor" foi construída a partir do Código de Menores de 1927. Durante o final do século XIX e início do XX, o Estado desenvolveu várias ferramentas de controle social para lidar com a crescente população pobre das grandes cidades, que eram vistas como "classes perigosas" (ALVAREZ, 2002, p.693). Um dos controles sociais utilizados durante quase todo século $X X$ foi o Código de Menores, uma legislação criada sob o discurso de "salvar" as crianças e adolescentes, mas que na prática criminalizava a pobreza. Durante esse período, o Estado fez uma opção de limitar a escolarização das classes populares, ao mesmo tempo em que apostou na polícia, no direito, na saúde e na assistência como forma de controle e higienização social. Para Saraiva (2006), a Doutrina de Situação Irregular, criada a partir do Código de Menores de 1927, estabelecia uma divisão, uma distinção legal entre as crianças e adolescentes de um lado e os "menores" de outro5.

\footnotetext{
${ }^{3}$ Fundação de atendimento Socioeducativo do Rio Grande do Sul.

${ }^{4}$ A escolaridade prevista para faixa etária entre 15 a 17 anos, é ensino Médio em andamento.

${ }^{5}$ As crianças e adolescentes eram os que estavam em situação regular; tidos como incapazes, eram ignorados pela lei. Os "menores" eram os que estavam em situação irregular - no contexto de abandono, pobreza, violência, criminalidade e moralmente suspeito - e por isso eram objetos da lei.
} 
A Constituição de 1988 (BRASIL, 1988) e o Estatuto da Criança e do Adolescente (BRASIL, 1990) romperam com esses procedimentos do menorismo. Todos os seres humanos com menos de 18 anos passam a ostentar a condição de sujeitos de direitos e reconhecidos em uma condição peculiar de desenvolvimento. Além disso, são considerados prioridade absoluta. A partir de uma nova legislação nacional que inicia após a redemocratização, a escola também abre suas portas, deixa para trás a sua função de apenas transmitir conteúdos prontos e acabados e passa a assumir um decisivo papel social, tendo como objetivo básico o "pleno desenvolvimento do educando, seu preparo para o exercício da cidadania e sua qualificação para o trabalho" (BRASIL, 1996, p.1)

Tanto a educação quanto a socioeducação são desenvolvidas dentro de uma perspectiva de Proteção Integral com o objetivo de formar cidadãos (BRASIL, 2012). No entanto, hoje parece estarmos vivendo ainda alguns resquícios de um passado recente, que segue se reproduzindo com novos discursos e práticas. Mesmo a educação sendo um direito público subjetivo garantido na Constituição Cidadã, são esses jovens das periferias, chamados de problemáticos, que seguem tendo seu direito negligenciado e terminam fora da escola.

Nos ambientes socioeducativos de privação de liberdade, a permanência na educação formal opera-se em uma espécie de marcador de "bom comportamento", que pode influenciar as avaliações técnicas sobre a permanência do jovem em internação ou na sua progressão para o meio aberto. Contudo, ao progredir de regime e ser transferido para o meio aberto, esse mesmo jovem encontra grandes dificuldades de dar continuidade para a sua trajetória escolar, seja pelas "portas fechadas" encontradas pelas escolas, seja pela dificuldade em encontrar atrativos que motivam a sua permanência na escola.

Sabemos que a tensão na relação entre juventude, adolescência e as escolas é um fenômeno multifatorial que as pesquisas estão apenas iniciando a aprofundar. Nosso estudo busca analisar a relação entre os jovens em conflito com a lei e a escola a partir do conceito de estigma, mas, assim como Dayrell, entendemos que é um fenômeno mais complexo.

(...) um primeiro passo é constatar que a relação da juventude com a escola não se explica em si mesma: o problema não se reduz nem apenas aos jovens, nem apenas à escola, como as análises lineares tendem a conceber. Tenho como hipótese que as tensões e os desafios existentes na relação atual da juventude com a escola são expressões de mutações profundas que vêm ocorrendo na sociedade ocidental, que afetam diretamente as instituições e os processos de socialização das novas gerações, interferindo na produção social dos indivíduos, nos seus tempos e espaços. (DAYRELL, 2007, pág. 1105)

Assim, partindo do entendimento de que há grandes desafios para a execução da educação escolar em ambientes socioeducativos, esse artigo se propõe a analisar de que maneira esses desafios aparecem na execução das medidas socioeducativas de meio aberto que, muitas vezes, compreende jovens egressos do sistema de privação de liberdade. 


\section{CAMINHOS METODOLÓGICOS}

Com o intuito de analisar de que maneira se apresentam os desafios para a efetivação do direito à educação no meio aberto, partiu-se da experiência de duas unidades de execução de medidas socioeducativas de meio aberto no Rio Grande do Sul: O Programa de Prestação de Serviços à Comunidade da Universidade Federal do Rio Grande do Sul (PPSC/UFRGS) e a Casa da Juventude Mathias Velho e Harmonia, da Secretaria de Segurança Pública e Cidadania do Município de Canoas (CJM).

O PPSC/UFRGS existe desde 1997, e tem como principal objetivo acolher adolescentes autores de ato infracional para o cumprimento da medida socioeducativa de Prestação de Serviços à Comunidade. Funciona como um projeto de extensão universitária e desde 2017 integra o CIESS Centro Interdisciplinar de Educação Social e Socioeducação da Faculdade de Educação da UFRGS.

A Casa da Juventude Mathias Velho e Harmonia foi um projeto da Secretaria Municipal de Segurança Pública com Cidadania do Município de Canoas (RS), criado no contexto do Programa Nacional de Segurança Pública Cidadã(Pronasci) e executado pela Fundação La Salle. O projeto atendia jovens marcados por situações de violência e atuava como uma unidade de execução de medidas socioeducativas de prestação de serviços à comunidade dentro de um dos bairros com maiores índices de letalidade juvenil no município. O projeto funcionou de 2012 a 2017.

Foram utilizados como principal fonte de dados relatos de educadores sociais e técnicos responsáveis pelo acompanhamento dos jovens nas duas unidades, sem um recorte temporal específico. Os acompanhamentos se deram em situações variadas, como na escola, no Centro de Referência Especializada de Assistência Social (CREAs), no Centro de Atenção Psicossocial (CAPs), em audiências judiciais, em idas para fazer documentos (Certidão de Nascimento, RG, CPF, Carteira de Trabalho, Título de Eleitor), em cursos profissionalizantes, em acompanhamentos na FASE, no Programa com egressos da FASE, Semiliberdade, em circulações na rua, em postos de saúde, em círculos familiares e mesmo nos atendimentos previstos na própria execução da medida. Esses acompanhamentos são registrados em forma de relatos nas fichas de cada adolescente atendido. $O$ nosso foco, no exame desses relatos, foi identificar situações envolvendo a educação formal.

Para além de apenas ser um relatório formal dos encaminhamentos realizados, muitas vezes esses relatos de acompanhamento trazem impressões, observações e até sentimentos vividos pelo profissional ao realizar aquele acompanhamento. Esse modelo de escrita não era realizado por todos os profissionais das unidades, mas a sua prática era estimulada pelas coordenações dos serviços como forma de gerar espaços e momentos de reflexão sobre o trabalho realizado com esses jovens. No caso do PPSC, por ser um programa inserido dentro da universidade - tendo como trabalhadores professores, técnicos, e estudantes de graduação ou pós-graduação da própria universidade - a prática da sistematização dos relatos era ainda mais presente. 


\section{PORTAS FECHADAS PELAS ESCOLAS}

Mesmo que a permanência na escola, em muitos casos, seja condição para que o jovem cumpra a sua medida socioeducativa em meio aberto, os dados sugerem que grande parte dos jovens em prestação no meio aberto encontra-se evadido da escola formal. ${ }^{6}$

Apesar de muitas vezes a família ou apenas o jovem serem culpabilizados por essa ausência no espaço escolar, como se a falta de motivação explicasse por si só o fenômeno, o que se apresenta com frequência no cotidiano das unidades de execução é a dificuldade de conseguir vagas para os esses jovens em conflito nas escolas da rede pública.

Os relatos apresentados a seguir demonstram as dificuldades encontradas pelas equipes de trabalho das unidades de execução de PSC em conseguir inserir ou reinserir os jovens em conflito com a lei na educação formal.

Chegando na escola, falei com o guarda municipal e disse-lhe que iria na secretaria. Entrando na secretaria aproximei-me de um guichê de atendimento e enxerguei ao fundo uma mulher de meia idade, que me perguntou sentada mesmo de onde estava, o que eu queria. Respondi que precisava falar com o coordenador da EJA. Ela foi logo me dizendo: "não tem vaga". Respondi que mesmo assim eu gostaria de falar com a pessoa responsável por que tinha um encaminhamento. Ela reagiu com uma expressão não muito agradável e me disse que passasse. Também pediume o encaminhamento. Depois de ler o documento perguntou-me: "por que essa escola?". Respondi que dois fatores foram levados em consideração na escolha da escola: o primeiro deles seria a vontade do adolescente e 0 segundo a proximidade da escola da residência do adolescente. A senhora perguntou, então, que ato infracional ele havia cometido. Respondi que não lembrava, mas tínhamos anotado e aproveitei para perguntar se aquela informação era relevante. Como se não tivesse ouvido minha fala voltou a perguntar sobre $o$ ato infracional. Perguntei se esta informação faria diferença para a escola e ela afirmou: "não há vagas". Foi então que solicitei que ela assinasse o formulário de solicitação de atendimento, informando a não existência da vaga. Neste momento fui encaminhado ao diretor da escola que foi muito atencioso e que prometeu incluir o nome do adolescente na longa lista de espera. (Relato de Acompanhamento - arquivo PPSC/UFRGS).

\footnotetext{
$6 \mathrm{Na}$ Casa da Juventude Mathias Velho e Harmonia, por exemplo, 19 dos 30 jovens que estavam em cumprimento de medida socioeducativa no primeiro semestre de 2016 estavam em situação de evasão escolar. (KOERICH, 2018)
} 
Conforme o combinado com o jovem no último atendimento, comecei os encaminhamentos no intuito de construir o retorno ao espaço escolar. Durante o atendimento, o jovem disse que poderia voltar a escola que frequentava antes de sua internação na FASE. Ligo para a escola, com a esperança de que o seu retorno possa ser imediato. A secretária que me atende diz que preciso falar com a diretora e que ela não está disponível no momento, mas que me retorna. Depois de mais uma semana esperando seu retorno, ligo novamente para a escola. Na terceira ligação, consigo falar com ela, explico a situação e pergunto se ela pode me receber pessoalmente para conversarmos sobre o assunto. Ela responde que "não adianta" matricular esse jovem, porque ele não vai permanecer. Continua, ainda, por um tempo reclamando do comportamento do jovem e dizendo que ele "não quer nada com nada". Sigo insistindo em uma conversa presencial, e ela desabafa que "o EJA não é mais como antigamente. Era pra ser pros trabalhadores, mas agora só tem que atender esse tipo de jovem". Posiciono-me no sentido de ressaltar o direito à educação básica para todos, e do dever do Estado em garantir esse direito e, ainda, como se trata de um jovem com menos de 18 anos, a sua permanência na escola é obrigatória e insisto uma última vez em irmos até a escola. Ela finaliza a ligação dizendo que pode nos receber, mas que ela não tem vagas de EJA naquela escola, e sugere que eu ligue para a Secretaria de Educação. (Relato de acompanhamento - arquivo CJ Mathias Vellho e Harmonia)

(...) fiquei suplicando uma vaga na escola para o adolescente do PPSC para essa a funcionária que eu já conhecia... então ela abriu uma planilha assustadora com tantos nomes esperando esse ingresso... aí comecei a desfiar o rosário... contei tudo o que temos vivido, com essas situações ao solicitar as vagas para os jovens em medidas socioeducativa e como não temos conseguido (...). Ela colocou o nome do jovem que eu estava acompanhando nessa planilha, uma longa fila de espera (...). Ressaltei novamente para ela: são solicitações que vem como medida protetiva... e fui fazendo a ladaia... que a gente vive, aí.. ela trouxe que há uma única lista, que é essa, e que os que vem encaminhados pelo PEMSE7 são avaliados antes de entrar na escola pelo serviço de orientação - uma entrevista com eles e seus responsáveis para ver o comprometimento e tal... ela me orientou a deixar o adolescente

\footnotetext{
${ }^{7}$ Programa Municipal de Execução de Medidas Socioeducativas de Meio Aberto
} 
como uma indicação da UFRGS, mas não citar nesse momento que era do PEMSE... que ela achava melhor... (Relato de Acompanhamento - arquivo PPSC/UFRGS).

Segundo nos apontam esses relatos, as barreiras para os jovens em cumprimento de medida estão relacionadas com a desconfiança em relação a sua responsabilidade e com o perigo que possam representar. O "perfil de jovem" a que se referem as escolas sugere um processo de seleção, balizado pelo merecimento do jovem em estar naquele espaço. A escola a que se refere o último relato criou inclusive um mecanismo para operar essa seleção: uma entrevista com os pais e com o jovem, que tem como finalidade avaliar a responsabilidade dele com essa vaga.

Não estamos olhando aqui para um direito: esses jovens, para ingressarem na escola, devem merecer, e mais, devem convencer que estão determinados a seguir as regras da escola e se concentrarem nos estudos. A sugestão da professora do último relato é a de omitir no encaminhamento a informação de que esse jovem está em cumprimento de medida socioeducativa, como uma forma de "ajudar" a técnica do programa a conseguir a vaga na escola.

As posturas dos profissionais das escolas sugerem que, para além do debate já complexo sobre o processo de juvenilização da EJA (CARRANO, 2007, p.2) há ainda uma divisão entre os jovens "merecedores" e aqueles que "não adianta matricular porque não vão permanecer".

Esses mecanismos de seleção não estão presentes apenas nas escolas, mas podem ser encontrados também em outras instituições que tem como objetivo garantir o direito à educação para a população, como sugere o relato a seguir:

Fui hoje com um adolescente na secretaria de educação do Estado do RS. Fomos atendidos por uma funcionária. Informei que buscávamos uma vaga em determinada Escola e ela foi logo dizendo que lá não tinha EJA. Ressaltamos que o adolescente não queria EJA, queria estudar na escola regular no diurno. Ela afirmou que a escola não iria aceitá-lo em função da sua idade - 16 anos - e acrescentou: "com quinze ele já pode ir para a EJA". De repente a funcionária começou a fazer um discurso voltado para $o$ adolescente. Disse que eles não vão à escola e depois não tem como estudar de dia e que o Estado faz a parte dele; que hoje os adolescentes mandam nos pais. Disse-Ihe que era obrigação do Estado informar-se sobre os adolescentes que estavam fora da escola. Respondeu: "o Estado vai. Para isso existe o conselho tutelar. Depois de muitas discussões, resolvi mostrar a ela o papel de encaminhamento do PEMSE/Judiciário. O adolescente explicou que estava matriculado em uma Escola, mas que não queria estudar lá por que era à noite e por que corria risco de vida. A 
funcionária recomendou ao adolescente que "não se envolvesse com esses caras", desconsiderando que são todos moradores da mesma região. Afirmou que "a culpa é do adolescente que não estuda e dos seus pais, o estado faz a sua parte". Depois de muita resistência e um enorme repertório de perguntas, a funcionária ligou para a escola que o adolescente queria. Depois de uma longa espera, voltou e disse que não quiseram aceitá-lo, pois ele já teria sido aluno da escola e que acabou saindo por envolvimento com o tráfico. $O$ adolescente argumentou que isso não era verdade e indagou quem teria dado a informação? Ela não respondeu. $O$ adolescente afirmou que saiu de escola, na época, por que ganhou uma bolsa em uma outra Instituição escolar privada. A funcionária quis saber por que ele havia saído dessa Instituição? Depois disso voltou a falar que ele deveria estudar na EJA e o adolescente voltou a dizer que não gostaria de estudar à noite. Por fim, a funcionária orientou-o a retornar num outro dia com um responsável para tentarem a vaga. (Relato de Acompanhamento - arquivo PPSC/UFRGS).

De acordo com a Lei de Diretrizes e Bases da Educação (Lei n 9394, 1996), a Educação de Jovens e Adultos é uma modalidade de ensino de caráter acelerado destinada para aqueles que "não tiveram acesso ou continuidade dos estudos no ensino fundamental e médio na idade própria" (BRASIL, 1996, seção 5, art. 37). A resolução $n^{\circ} 3$ de 2010, do Conselho Nacional de Educação, estabelece que a idade mínima para o ingresso do jovem na Educação de Jovens e Adultos é de 15 anos. Contudo, não é consenso entre teóricos da educação se, ao completar a idade mínima para acesso da Educação de Jovens e Adultos, o jovem deve obrigatoriamente trocar de modalidade de ensino.

Apesar de polêmico no campo teórico, essa prática é recorrente no cotidiano da educação básica e, muitas vezes, mesmo que o jovem e a família se pronuncie contrária a essa mudança, as direções das escolas não permitem a permanência do jovem no ensino regular.

A adolescente veio com a mãe, no programa, solicitando ajuda para conseguir escola para estudar. Desejavam a determinada escola, pois era perto da residência deles, e ela não precisaria gastar em passagem. A mãe também queria que não fosse EJA e a noite. Eu e minha colega fomos então com a adolescente à escola, tentar uma vaga. Ela explicou que já havia ido com a mãe nessa escola, e disseram que não tinha vaga. Chegando a escola, na secretaria pedimos informações sobre vagas e fomos encaminhados para uma sala perto da entrada, para falar com uma funcionária da escola. Ela nos falou que já haviam encaminhado um 
relatório com as vagas para a central de vagas. Teriam 10 vagas para a oitava série no turno da tarde. A adolescente deveria ir a Central de vagas com um responsável e solicitar a vaga na escola. A Central então telefonaria para a escola, que confirmando a vaga, enviaria uma carta para a solicitante poder começar as aulas. Mesmo nos assegurando a vaga, a funcionária aparentou não ter gostado da possibilidade de ter a adolescente como nova aluna. Fez perguntas de porque não estava na escola e porque tinha saído da última. Quando soube que ela havia brigado com outra menina na antiga escola ela perguntou: Não estão me trazendo um problema né!? Falamos que éramos da UFRGS e trabalhávamos num programa que executa medidas sócio educativas, e que continuaríamos acompanhando a adolescente na escola. Ela pareceu mais aliviada (...) Durante a conversa, a diretora parecia querer intimidar a adolescente, falando das regras rígidas da escola, não pode ir ao banheiro na hora do recreio, e que sempre estariam sendo vigiados. Falou que se ela arranjasse alguma briga lá, descobririam imediatamente e ela seria suspensa. Saindo da escola perguntei à adolescente a impressão que ela teve da escola, ela só me olhou e fez um muxoxo. Certamente não foi uma boa recepção. (Relato de Acompanhamento - arquivo PPSC/UFRGS).

A postura das escolas ou instituições de educação ao receberem jovens em conflito com a lei parece ser a de explicitar as regras do local imediatamente. Opera, nesse sentido, uma lógica que faz crer que os jovens, por estarem em conflito com a lei, não conseguiriam seguir as regras do espaço escolar.

Todos os relatos apresentados possuem, como ponto de convergência, práticas que lembram um fechar de portas para esses jovens e que ocorre a partir da reprodução de um estigma social voltado para a juventude em conflito com a lei.

\section{EDUCAÇÃO DE JOVENS EM CONFLITO COM A LEI E ESTIGMA SOCIAL}

Ao identificar nos relatos de acompanhamento posturas estigmatizantes, buscamos nesta seção desenvolver reflexões teóricas acerca do conceito de estigma, bem como analisar de que forma esse conceito pode ser uma das chaves explicativas possíveis para compreender a dificuldade das escolas em receber os jovens em cumprimento de medida socioeducativa ou que já passaram por ela.

Goffman conceitua o estigma como uma característica depreciativa que insere o sujeito em uma determinada categoria tida como menos desejável: "Assim deixamos de considerá-lo criatura 
comum e total, reduzindo-o a uma pessoa estragada e diminuída." (GOFFMAN, 1988, p. 12). O autor remonta o conceito de estigma à Grécia antiga, quando se infligiam marcas, como cortes ou queimaduras, um alerta visível de que aquela pessoa era um escravo, um criminoso ou um traidor. Atualmente, segundo o autor, o estigma continua com uma função muito parecida. (GOFFMAN, 1988, p. 5).

É interessante observar que o verbo "infringir", que significa quebrar, violar, desrespeitar, quando entra em contato com esses jovens, se transforma num adjetivo ou substantivo: "infrator", carregando o peso da permanência e não mais descrevendo um ato que tem início e fim. O termo "infrator", então, não fala apenas do momento atual, mas também do passado e do futuro. Assim, o infrator não está simplesmente relacionado à ação de infringir, mas a um modo de ser, de existir. $\mathrm{O}$ estigma tem esse poder, de naturalizar atributos negativos e de reduzir a estes o sujeito estigmatizado.

Nos relatos apresentados anteriormente, ficam evidentes marcas de que, no ambiente escolar, os jovens em cumprimento de medida socioeducativa são, antes que tudo, infratores. Fica difícil para a escola, assim, enxergar nesses sujeitos uma pessoa com direito à educação. Muitas vezes e em muitos lugares, esses jovens não são vistos como sujeitos com plenos direitos. Essa cidadania menor, ou não cidadania, por si só já é ultrajante perante um Estado de direito. Por que, mesmo após um processo histórico de muita luta para se garantir direitos a todos os cidadãos, parece haver uma resistência, e determinadas categorias não têm estes direitos respeitados, mesmo que isto esteja definido a tinta na legislação?

Elias e Scotson (1994) nos ajudam nesta questão. Eles chamam a atenção para o fato de o estigma poder ser lançado por uma categoria ou grupo a outro, criando uma barreira emocional, uma relação entre superiores e inferiores, difícil de ser removida. Revelam que a estigmatização é uma relação de poder: o estigma social imposto por um grupo poderoso a outro, costuma penetrar na auto-imagem deste último e, com isso, enfraquecê-lo e desarmá-lo. Para os autores, a construção do estigma social passa pela construção de uma idéia de "nós" e "eles", e uma posterior separação de atributos que cada uma dessas categorias comporta.

As instituições de educação que fecham as portas para os jovens em cumprimento de medidas socioeducativas operam seguindo essa mesma lógica. Existe, assim, aqueles jovens que merecem estudar, a quem o direito à educação deve ser garantido e os "outros", que mesmo que tenham o direito à educação, não "deveriam" estar na escola "normal".

O relato a seguir ajuda a demonstrar como essa separação é presente no cotidianos da educação básica.

\section{(...) A diretora perguntou se eu achava que o aluno se adaptaria a escola "normal", depois de ter ficado em internação e ter estudo em uma escola "especifica para esse público", na FASE. Respondi que acreditava que a permanência de jovens no ambiente escolar é sempre um desafio e por isso era necessário o empenho de todos. Ela me olhou como quem vai}


confidenciar algo e me disse que temia pelos outros adolescentes do colégio, que poderiam se influenciar. Falei um pouco para ela que independente dos nossos receios, agora o jovem estava no meio aberto, $e$ precisariamos garantir o seu acesso a educação. Como se compartilhassemos de uma concepção, ela me disse "Tinha que ter uma escola só para eles também aqui fora, não acha?". Limitei-me a responder que não tinha certeza se seria o melhor. (Relato de acompanhamento, Casa da Juventude Mathias Velho e Harmonia)

A existência de uma escola "só para eles", como sugeriu a diretora poderia até contribuir para o desenvolvimento de metodologias especializadas em jovens envolvidos em situações infracionais, mas reforçaria o seu posicionamento social de ser "diferente" dos demais jovens. A dificuldade de inseri-los na escola parte de um entendimento de que a presença de um (ou mais ) ato(s) infracional(is) faria com que estar na escola já não fizesse mais sentido, de acordo com o que se espera que aquele espaço seja para os adolescentes: um espaço de preparação para a vida "adulta".

Ao analisar o operacionalização do estigma em uma pequena comunidade, Elias e Scotson (1994) observaram que a população mais antiga classificava os recém chegados como outsiders e viam eles, normalmente, como pessoas ligadas à ilegalidade, indignos de confiança, indisciplinados e desordeiros. (ELIAS; SCOTSON, 1994, p. 27) Tanto Goffman quanto Elias e Scotson salientam o quanto o estigma está ligado à norma social ou, melhor dizendo, à quebra dela. Assim, só podemos entender os estigmas fabricados em uma determinada sociedade, se entendermos primeiro seu caldo cultural, seu histórico, suas regras, seu padrão de vida.

Nesse sentido, o discurso que estigmatiza não tem como principal objetivo a inferiorização do outro, e sim a reafirmação dos limites que a norma social estabelece. E não apenas dos limites, mas também de um modo de vida e de determinados valores. Por isso não é estranho encontrar um discurso similar em diferentes escolas e profissionais da educação receosos em receber um jovem que já praticou algum ato infracional, pois eles partilham de um caldo cultural amplo que historicamente foi atravessado por discursos que construíram a figura temida do "menor infrator".

Esses discursos, que há muito vem se sedimentando no imaginário da sociedade brasileira, seguem sendo reproduzidos na mídia, nas escolas, nas políticas públicas, e na justiça, reforçando esse estigma. Esses discursos funcionam a partir das relações de poder. Para Foucault o poder não é um fenômeno de dominação maciço e homogêneo. Não pode ser exercido exclusivamente por uma pessoa, nem por um grupo, nem por uma classe. O poder circula, funciona em cadeia. Exercese o poder em rede, os indivíduos estão sempre em posição de ser submetidos pelo poder, assim como também podem exercê-lo. (FOUCAULT, 2005, p. 35). No entanto, isso não quer dizer que ele é democrático ou que funciona ao acaso; não quer dizer que é bem distribuído e nem que ele não 
seja direcionável. São relações de poder que submetem, que legitimam formas de ser, formas de hierarquizar, formas de se comportar, e assim constroem uma norma.

Ou seja, estamos tratando de discursos que têm efeitos na prática, como a exclusão de jovens em conflito com a lei das escolas, que constroem uma "verdade" difícil de refutar sobre quem são esses sujeitos. Foucault coloca que o poder não pode existir "nem estabelecer-se, nem funcionar sem uma produção, uma acumulação, uma circulação, um funcionamento do discurso verdadeiro." (FOUCAULT, 2005, p. 28) As múltiplas relações de poder que perpassam, caracterizam e constituem o corpo social, estão todas atreladas aos discursos de verdade que funcionam a partir e através do poder. Discursos de verdade são aqueles que trazem consigo efeitos de verdade, e é a partir deles que somos julgados, condenados, classificados cotidianamente, impelidos a tarefas e destinados a certa maneira de viver. (FOUCAULT, 2005, p. 29).

Na modernidade, os principais discursos de verdade são aqueles embasados e certificados nos saberes, são eles que legitimam essas diferentes narrativas e versões de fatos como verdadeiros, como realidade. Ou seja, esses discursos funcionam, são ações, têm efeitos práticos. O seu discurso legítimo, discurso de verdade, será o discurso da regra, o discurso do que é natural, o discurso da norma. (FOUCAULT, 2005, p. 45) Isso é importante para nossa discussão, porque são esses discursos que convencem, que "cheiram a verdade", que são utilizados para estigmatizar outros grupos.

Foucault nos serve então para entender como esses dispositivos atuam em diversos níveis, produzindo efeitos reais, como políticas de Estado, padrões de comportamento, inimigos da sociedade, hierarquização social, naturalização da desigualdade, formação dos sujeitos etc. Entendo que, para este artigo, é muito importante perceber estas articulações, pois me parece que o estigma atua no nível dos discursos, alimentando ao mesmo tempo toda essa engrenagem.

É difícil definir o que seja estigma, de encontrar como se dá seu funcionamento e seus limites. Em primeiro lugar, porque ele está enraizado na sociedade como um discurso de verdade. Ele está misturado nas nossas práticas e julgamentos cotidianos, faz parte de nossa cultura, ou está muito bem misturado a ela. Difícil analisar onde começa e onde termina. Mas podemos enxergar seus efeitos. Ao ler os relatos de acompanhamento dos jovens, podemos perceber um pouco a forma como os discursos estigmatizantes os atinge, como ele deturpa e simplifica suas imagens e as consequências que isso provoca (menos direitos, violência, desumanização, tidos como não confiáveis).

É importante salientar, também, que as práticas de estigma não apenas fecham as portas para os jovens em cumprimento de medida socioeducativa ao negarem vaga ou tentarem transferir para outras escolas, a prática cotidiana de estigmatização desses jovens produz neles próprios a sensação de que a escola "não é lugar" para si. 


\section{CONSIDERAÇÕES FINAIS}

A educação é um direito de todos os cidadãos e, quando falamos de cidadão de até 18 anos, ela é, também uma obrigatoriedade. Contudo, a garantia do direito à educação para alguns sujeitos é particularmente desafiadora. É que ocorre nos contextos de privação de liberdade ou nos de restrição de liberdade, que aqui defendemos também incluir as execuções de medidas socioeducativas no meio aberto.

Buscou-se, assim, a partir de relatos de acompanhamentos de jovens em duas unidades de execução de medidas de prestação de serviços à comunidade, compreender de que forma apresentam-se as dificuldades para a continuidade da trajetória escolar de jovens que cometeram atos infracionais.

A análise dos relatos sugerem que, mesmo quando o jovem está cumprindo sua medida em meio aberto encontra, na maioria das vezes, portas fechadas nas escolas e instituições de educação. Assim, acreditamos que os desafios da educação em contexto de privação de liberdade abrangem também a transição para o meio aberto ou mesmo a liberdade quando falamos da socioeducação.

Esse fato nos mostra, então, que alguns dos desafios presentes na intersecção entre escolaridade e restrição de liberdade não está relacionada, somente, com o espaço da privação da liberdade em si, e sim também com os sujeitos que a compõe, que carregam o estigma de serem infratores mesmo quando estão no meio aberto. Se, por um lado, discursos do senso comum reforçam cotidianamente que a falta de educação pode gerar problemas de segurança pública, por outro, entende como perigosa a convivência dos jovens em conflito com a lei com os demais no espaço educacional.

O que se evidencia, dessa forma, é a reprodução de práticas estigmatizadores, que classifica os jovens que cometeram um ou mais ato(s) infracional(is) como menos merecedor de estar na escola e como um perigo constante para o ambiente escolar.

Nesse sentido, temos que avançar, não apenas na garantia da educação dentro dos espaços de privação de liberdade e suas metodologias de trabalho, como também na transição e garantia que estes sujeitos possam dar sequência nos seus estudos no ambiente de liberdade. 


\section{REFERÊNCIAS}

ALVAREZ, Marcos César. A criminologia no Brasil ou Como tratar Desigualmente os Desiguais. Dados. Rio de Janeiro, v.45, n.4, 2002.

2. BRASIL. Constituição da República Federativa do Brasil de 1988. Diário Oficial da União, Brasília, 5 de outubro de 1988.

3. BRASIL. Lei n. 8.069, de 13 de julho de 1990. Dispõe sobre o Estatuto da Criança e do Adolescente e dá outras providências. Diário Oficial da União, Brasília, 16. Julho 1990

4. BRASIL, Lei n. 9394, de 20 de dezembro de 1996. Estabelece as diretrizes e bases da educação nacional. Diário Oficial da União, Brasília, 20 de dezembro de 1996.

5. BRASIL Lei n. 12.594, de 18 de janeiro de 2012. Institui o Sistema Nacional de Atendimento Socioeducativo (Sinase). Dispõe sobre a regulamentação das Medidas Socioeducativas. Diário Oficial da União, Brasília, 19 janeiro 2012.

BRASIL. Atendimento Socioeducativo ao Adolescente em Conflito com a Lei. Levantamento Nacional de 2014. Secretaria dos Direitos Humanos. Brasília, 2017.

7. CARRANO, Paulo César. Educação de Jovens e Adultos e Juventude: o desafio de compreender os sentidos da presença dos jovens na escola da "segunda chance". In: REVEJ@ Revista de Educação de Jovens e adultos, v. 1, ago. 2007. Belo Horizonte.

8. DAYRELL, Juarez. A escola "faz" as juventudes? Reflexões em torno da socialização juvenil. Educação Social, Campinas, vol. 28, n. 100 - Especial, p. 1105-1128, out. 2007.

9. ELIAS, Norbert. SCOTSON, John L. Os estabelecidos e os outsiders: sociologia das relações de poder a partir de uma pequena comunidade. Rio de Janeiro, RJ : J. Zahar, 2000. 224 p.

10. FOUCAULT, Michel. Em Defesa da Sociedade: curso no Collège de France (1975- 1976). São Paulo: Martins Fontes, 2005. 
11. GOFFMAN, Erving. Estigma: notas sobre a manipulação da identidade deteriorada. 4. ed. Rio de Janeiro: Guanabara, 1988. 158 p.

12. IBGE - Instituto Brasileiro de Geografia e Estatística. Pesquisa Nacional de Amostra por Domicílios. 2004 a 2012; Elaborado por MEC/Inep/DEED.

13. KOERICH, Bruna Rossi. Segurança Pública e Cidadania na execução das medidas socioeducativas de meio aberto. Revista Novos Olhares Sociais. Universidade Federal do Recôncavo da Bahia, 2018.

14. NARDI, Fernanda Ludke; JAHN, Guilherme Machado; DELL'AGLIO, Débora Dalbosco. Perfil de adolescentes em privação de liberdade: eventos estressores, uso de drogas e expectativas de futuro. Psicologia em Revista. Belo Horizonte, v. 20, n. 1, p. 116-137, abr. 2014

15. SARAIVA, João Batista Costa. Compêndio de direito penal juvenil: adolescente e ato infracional. Porto Alegre, Livraria do Advogado ED., 2006.

16. VIDAL, Alex da Silva. Adolescentes em medida socioeducativa: um estudo sobre estigma. 2014. 161f. Dissertação (Mestrado em Educação) - UFRGS, Porto Alegre.

\section{Bruna Rossi Koerich}

Bacharela em Ciências Sociais pela Universidade Federal do Rio Grande do Sul. Mestra em Ciências Sociais pela Pontifícia Universidade Católica do Rio Grande do Sul. Foi coordenadora da Casa da Juventude Mathias Velho e Harmonia no município de Canoas/RS. Atualmente é coordenadora do Centro de Juventude Lomba do Pinheiro do Programa de Oportunidades e Direitos (POD) do Estado do Rio Grande do Sul. Compõe a Frente de Enfrentamento à Mortalidade Juvenil do Município de Porto Alegre. Integrante do Idades - Grupo de Estudos e Pesquisas em Antropologia (PUCRS). 


\section{Alex da Silva Vidal}

Historiador, Mestre e Doutorando em Educação (UFRGS), Bolsista da CAPES; Atua no Programa de Prestação de Serviços à Comunidade (PPSC/UFRGS) desde 2010; Integrante do Programa Interdepartamental de Práticas com Adolescentes em Conflito com a Lei (PIPA/UFRGS) e do CIESS (Centro Interdisciplinar de Educação Social e Socioeducação), Órgão Auxiliar da Faculdade de Educação (UFRGS).

\section{Como citar este documento:}

ROSSI KOERICH, Bruna; DA SILVA VIDAL, Alex. Portas fechadas no meio aberto: educação de jovens com restrição de liberdade. Reflexão e Ação, Santa Cruz do Sul, v. 27, n. 2, abr. 2019. ISSN 1982-9949. Disponível em: <https://online.unisc.br/seer/index.php/reflex/article/view/12628>. Acesso em: . doi:https://doi.org/10.17058/rea.v27i2.12628. 